\title{
THE NUMBERS OF PATHOGENIC BACILLI IN FAECES IN INTESTINAL DISEASES
}

\author{
By SCOTT THOMSON \\ The Public Health Laboratory, Cardiff \\ EXAMINATION OF FAECES
}

Faeces normally contain very large numbers of many bacterial species, and intestinal diseases are usually diagnosed by demonstrating pathogens among them. Simple methods of plating on non-selective media separate the several species by a more or less mechanical means. Selective culture media, on the other hand, inhibit the normal flora of the gut but allow the pathogens to grow and reveal their presence even when in small numbers.

Highly selective culture media are used to isolate salmonellae and dysentery bacilli, and new methods, to give more positive results, are constantly being described. For the bacteriological diagnosis of gastro-enteritis of babies caused by serologically identifiable varieties of Bacterium coli $(0111,055,026$, etc., with their various $H$ antigen combinations) there are no selective culture media, and the difficulty arises of separating pathogenic Bact. coli from harmless Bact. coli. In gastro-enteritis, however, the gut appears to harbour large numbers of the special Bact. coli, and as a rule the culture of the faeces on any suitable medium is virtually a pure culture of it. But for this fact it is doubtful if the aetiological role of these special varieties of Bact. coli in gastro-enteritis would have been suspected, and some bacteriologists doubt if the regular demonstration of these special varieties of Bact. coli in outbreaks of gastro-enteritis of babies is alone sufficient evidence to establish their virulence.

Gastro-enteritis is highly infectious among babies, and usual measures, including barrier nursing which would prevent the spread of other intestinal diseases, are inadequate. The high infectivity is believed by many to be due, in part at least, to the very large numbers of bacilli excreted in the faeces, and this belief implies that pathogens are not excreted in large numbers in other intestinal diseases. The alleged pathogenic varieties of Bact. coli appear to replace the normal Bact. coli and other flora of the gut, and the normal flora thus appears to be dominated by the pathogen. This is believed to be in contrast to the relationship in other intestinal diseases where the difficulty is to demonstrate the pathogen in the presence of the normal flora.

In an investigation to be reported later enumerations were made to study the ability of chemotherapeutic substances to suppress the large numbers of pathogenic Bact. coli in cases of gastro-enteritis. The expected large numbers were found, but a similar study of cases of dysentery, salmonella food poisoning and enteric fever showed the results not to be unique.

The demonstration of very large numbers of Salm. typhi and Salm. paratyphi B in the faeces of chronic carriers has already been reported (Thomson, 1954). 


\section{METHODS}

A $10 \%$ suspension of faeces, and from it tenfold dilutions up to $10^{-8}$, were made using a fresh sterile pipette for each step. One drop, 1/50 ml., of each dilution was allowed to fall on the surface of a suitable culture plate, and after incubation the colonies were identified and counted (Miles \& Misra, 1938). Ordinary MacConkey's medium was used for the enumeration of Bact. coli, deoxycholate citrate medium for dysentery bacilli, and brilliant green MacConkey's medium for Salm. paratyphi B and salmonellae of food poisoning. One colony from each case had been picked for precise identification. The other colonies in the Miles \& Misra counts were identified by slide-agglutination reaction.

In the case of salmonellae and shigellae on special media the appearance of the colonies was a great aid in diagnosis, and slide-agglutination reactions were made of representative colonies. As a rule the cultures made from the higher dilutions from which the counts were calculated were pure cultures on the special media used.

In the case of gastro-enteritis of babies, however, it was necessary to test by slideagglutination all the colonies from the dilution on which the count was based. The pathogenic varieties were thus identified by their ' $B$ ' antigen. The colonies of pathogenic varieties of Bact. coli often show differences from the non-pathogenic but the differences are not sufficient to be of great value. In the majority of cases the dilution from which the count was calculated was a pure culture of Bact. coli, 0111 or 055 , etc., but not infrequently pathogenic and non-pathogenic varieties were present in similar numbers. The problem of identifying a pathogenic variety when outnumbered by a non-pathogenic variety is discussed later.

\section{RESULTS}

\section{Numbers found in diseased persons}

\section{Gastro-enteritis of babies: fifty cases}

In the early stages of the disease there were on the average $1,000,000,000$ pathogenic Bact. coli per gram of faeces. By the technique used this meant that one drop of a one in a million dilution of faeces yielded twenty colonies on the culture plate. The counts ranged from $50,000,000$ to $10,000,000,000$ per gram of faeces.

In Miles \& Misra counts it is convenient to count between five and fifty colonies and the results can be recorded in the form 5 to 50 times $10^{x}$. This procedure allowed a simple comparison of counts in gastro-enteritis with those in dysentery, food poisoning and enteric fever.

In these cases of gastro-enteritis the counts, per gram, were 5 to 50 times $10^{9}$ in twelve cases, $10^{8}$ in twenty-six cases, $10^{7}$ in seven cases, and $10^{6}$ in five cases. Normal Bact. coli were often present in similar numbers, but rarely in the early stages did they outnumber the pathogens. When the pathogenic Bact. coli outnumbered the normal in the ratio of $10: 1$ it was possible to enumerate both with no great difficulty. When the ratio was 100:1 it was almost impossible to identify the normal Bact. coli yet they could have been present in normal numbers. (The numbers of Bact. 
coli in the gut of normal people are very variable, but $1,000,000$ to $500,000,000$ per gram are common.) Conversely, pathogenic varieties of Bact. coli can be present in faeces in large numbers, but if outnumbered more than 20:1 by normal Bact. coli they are not likely to be detected.

It is unfortunate that no selective culture medium exists to allow the demonstration of small numbers of pathogenic Bact. coli in faeces, and it is thus not possible to give a reliable negative report. As the two varieties, pathogen and normal, grow equally well on the same culture plate it is the ratio between the two that decides the reported result. A negative result is not reliable and the term 'scanty positive' has no meaning.

Ordinary MacConkey's medium was used for these tests, and with experience it was possible to detect differences in the appearances between the colonies of pathogenic varieties of Bact. coli and others. A medium containing sorbitol, preferred by some workers, was not found of added value in our hands. In the series there were thirty-seven cases infected with Bact. coli $055 \mathrm{~B} 5 \mathrm{H} \mathrm{2}$, four infected with $0111 \mathrm{~B} 4 \mathrm{H} 12$ and nine with $026 \mathrm{~B} 6 \mathrm{H} 11$.

\section{Sonne dysentery: twenty-three cases}

The numbers of Shigella sonnei per gram of faeces were 5 to 50 times $10^{8}$ in two cases, $10^{7}$ in six cases, $10^{6}$ in eleven cases and $10^{5}$ in four cases. The numbers of bacilli per gram of faeces varied from 500,000 to $1,000,000,000$.

Dysentery bacilli and Bact. coli were usually present in approximately equal numbers. In four cases the dysentery bacilli outnumbered the Bact. coli; in nine cases the Bact. coli outnumbered the dysentery bacilli (usually only 10:1); in eight cases the same dilution yielded approximately equal numbers of Bact. coli and Sh. sonnei. Two of the cases yielded no Bact. coli from one drop of $1: 10$ dilution of faeces (less than 500 bacilli per gram), a result which was confirmed by culturing the inoculum in broth. In both these cases the specimens were very fluid and taken on the first day of illness.

\section{Salmonella food poisoning: twenty cases}

The findings in salmonella food poisoning were similar to those in Sonne dysentery. The numbers of salmonellae per gram of faeces were 5 to 50 times $10^{7}$ in five cases, $10^{6}$ in eight cases, $10^{5}$ in six cases and $10^{4}$ in one case. The counts ranged from 250,000 to $1,000,000,000$ per gram of faeces, and the salmonellae were not greatly outnumbered by the normal Bact. coli of the gut. There were sixteen cases of Salm. typhi-murium, two of Salm. thompson and two of Salm. bovis-morbificans.

\section{Paratyphoid fever: seven cases}

It was not possible to examine a series of cases from which specimens of faeces suitable for examination had been submitted before treatment was begun, but a few observations were possible.

It has for long been believed that the number of bacilli excreted in the faeces in the first week of illness is small, but it was not possible to find suitable specimens 
for examination to confirm this. In the later stages of the disease a number of examinations were made of untreated cases. The numbers of Salm. paratyphi $B$ per gram of faeces were 5 to 50 times $10^{8}$ in one case, $10^{7}$ in two cases, $10^{6}$ in three cases and $10^{4}$ in one case. Thus, while it was not possible to say that patients with paratyphoid fever regularly excrete large numbers of pathogens, it appeared that in some stages of the disease they may do so.

\section{Symptomless excreters}

It sometimes happens that healthy people are found to be temporarily excreting intestinal pathogens, and it was thought to be of some interest to know if they too harboured large numbers. It was suspected that the appraisal of the results might be difficult as symptomless excreters are identified at an undefined interval after infection. Small numbers might mean that the pathogens were disappearing after being present earlier in large numbers. In the event, however, surprisingly large numbers were again found.

\section{Pathogenic Bact. coli: thirteen cases}

Thirteen children and adults with no symptoms of illness were found to be excreting pathogenic strains of Bact. coli, and the numbers of bacilli per gram of faeces were the same as those found in sick persons. The counts ranged from $5,000,000$ to $10,000,000,000$ per gram, the counts being 5 to 50 times $10^{9}$ in four cases, $10^{8}$ in four cases, $10^{7}$ in four cases and $10^{6}$ in one case.

It is admittedly difficult to be sure that a small baby has not a mild degree of diarrhoea, but four of the symptomless excreters were adults and four were toddlers in a well-run residential nursery.

It does not follow, however, that all symptomless excreters of pathogenic varieties of Bact. coli harbour large numbers. If normal varieties of Bact. coli are present in large numbers, moderate numbers of the pathogenic varieties cannot be identified in the absence of a selective culture medium.

\section{Sh. sonnei: five cases}

The numbers of Sh. sonnei per gram of faeces were 5 to 50 times $10^{5}$ in two cases, $10^{4}$ in two cases and $10^{1}$ in one case. The counts ranged from 500 to $4,500,000$ per gram.

\section{Salmonellae (food poisoning): six cases}

The numbers of bacilli per gram of faeces were 5 to 50 times $10^{6}$ in one case, $10^{5}$ in three cases and $10^{4}$ in two cases.

\section{Salm. paratyphi B: seven cases}

These were household contacts of sick persons, but had almost certainly been infected at the same time as the patients. The counts were very low, all being less than 25,000 per gram. In three cases the paratyphoid bacilli were found only after growing in broth and the drop of $1: 10$ dilution of faeces yielded no colonies on the surface of a culture plate in the Miles \& Misra count. 
These symptomless excreters of Salm. paratyphi $B$, all of whom became negative within a week, had a positive Widal B.H. titre of $1 / 50$. In our experience a Widal result of this kind can be expected in casual excreters, and over many years it has been our experience that a Widal B.H. titre of $1 / 50$ in an uninoculated person is diagnostic of infection.

\section{IN VITRO EXPERIMENTS}

In intestinal infections there appear to be many more pathogens in the faeces than would be suspected from the descriptions of the methods used to demonstrate their presence. Special methods using selective culture media allow the detection of very small numbers of pathogens, but it does not follow, if a simple culture gives a negative result and a special technique a positive, that the pathogens are present in small numbers. The following examples illustrate this.

\section{Plating on selective and non-selective solid culture media}

MacConkey's medium is a good culture medium for Bact. coli, Streptococcus faecalis, salmonellae and dysentery bacilli; when brilliant green is added it becomes selective for salmonellae. Deoxycholate citrate medium is selective for both salmonellae and dysentery bacilli. If a specimen of faeces is plated out on MacConkey's medium and on a selective medium the latter may show a considerable number of colonies of a pathogen and the former an apparently pure culture of Bact. coli only. The appearance of the MacConkey plate suggests that the Bact. coli greatly outnumber the pathogen but this is not so as the preceding experiments have shown. An apparently pure culture of Bact. coli appears on MacConkey's medium when Bact. coli outnumbers the pathogen by as little as 10 or $20: 1$. The phenomenon is the rule and not the exception, and a few examples are quoted.

Salm. paratyphi B

A specimen of faeces contained per gram 200,000,000 Bact. coli and 10,000,000 Salm. paratyphi B. MacConkey's medium was used for the enumeration of Bact. coli and brilliant green MacConkey's medium for Salm. paratyphi $B$.

When the tenfold dilutions of faeces had been made for the enumerations one drop of each dilution was plated out on a whole plate of simple MacConkey's medium and spread in the usual way to get separation of colonies for the isolation of different species from a mixture. No colonies of Salm. paratyphi $B$ could be detected in the cultures made from the dilutions $10^{\circ}, 10^{-1}, 10^{-2}$ and $10^{-3}$ which appeared to be pure cultures of Bact. coli. The culture made from $10^{-4}$ dilution, however, showed Salm. paratyphi B in addition to the Bact. coli.

Salm. bovis-morbificans

A specimen of faeces contained $20,000,000$ Salm. bovis-morbificans and $10,000,000,000$ Bact. coli per gram. One drop of each of the tenfold dilutions made for the Miles \& Misra count was plated out on a whole plate of MacConkey's medium and none of these cultures revealed a salmonella. 


\section{Sh. sonnei}

A specimen of faeces contained equal numbers of Bact. coli and Sh. sonnei $\left(2,000,000,000\right.$ per gram), one drop of the $10^{-7}$ dilution of faeces yielding four colonies of each species. Cultures made on simple MacConkey's medium of a drop of each of the dilutions prepared for the Miles and Misra count showed only four or five colonies of dysentery bacilli on each plate, greatly outnumbered by Bact. coli except in the cultures made from the dilutions above $10^{-4}$.

Thus, plating similar amounts of faeces on selective culture media and ordinary MacConkey's medium shows large numbers of colonies of pathogens on the former and large numbers of colonies of Bact. coli on the latter. This observation is not new, but it has hitherto been believed that the apparently pure culture of Bact. coli on MacConkey's medium arose from an overwhelming dominance in numbers of Bact. coli in the specimen. Expressed in another way, it has hitherto been suspected that a rich culture of a pathogen on a selective medium would not be obtained from a small inoculum. These impressions appear to be wrong. The pathogens are usually not greatly outnumbered by Bact. coli in the faeces and the inability of ordinary MacConkey's medium to reveal this requires further study.

The results showed also that there was often an advantage in plating out a high dilution of the specimen, and a similar observation was previously recorded by Thomson (1954) when plating out specimens of faeces for Salm. typhi using deoxycholate citrate medium.

\section{Growth in fluid media.}

For routine use in the isolation of intestinal pathogens special fluid media such as selenite broth or tetrathionate broth are used. These media undoubtedly reveal the presence of small numbers of pathogens which would otherwise be missed but it would be wrong to conclude that specimens found positive only by culturing in these special broths harbour small numbers of the pathogen. The suspicion arises that much of the advantage of selenite broth and tetrathionate broth, etc., derives not from the special ingredients but from the fact that the medium is fluid.

During an outbreak of food poisoning (Salm. typhi-murium: Lennox, Harvey \& Thomson, 1954) a number of comparative tests were made 3 weeks after the onset. By this time most of the cases might have been expected to harbour small numbers of salmonellae and the specimens would be suitable for critical comparative tests especially as the cases had had only very mild diarrhoea for a day or two.

In the first trial specimens of faeces were inoculated into ordinary nutrient broth, selenite broth and on brilliant green MacConkey plates, care being taken to introduce equal amounts into the two fluid media. There were seventy-two specimens: forty-seven were positive on direct plating on brilliant green MacConkey's medium (the best in our opinion for salmonellae); fifty-four were positive from selenite broth; fifty were positive from nutrient broth.

In another trial specimens of faeces were inoculated into ordinary nutrient broth and selenite broth, and on deoxycholate citrate medium, care being taken to introduce equal volumes into the two fluid media. After incubation the two fluid 
culture media were subcultured on deoxycholate citrate plates and brilliant green MacConkey plates. There were thirty-two specimens examined with the following results :

Direct plating on deoxycholate citrate plates

1 positive

Nutrient broth subcultured on brilliant green MacConkey plates

Nutrient broth subcultured on deoxycholate citrate plates

27 positive

Selenite broth subcultured on brilliant green MacConkey plates

11 positive

Selenite broth subcultured on deoxycholate citrate plates

26 positive

9 positive

Thus the combination of ordinary nutrient broth and brilliant green MacConkey's medium was superior to the combination of selenite broth and deoxycholate citrate medium. By any combination ordinary nutrient broth was as good as selenite broth. The cultures on brilliant green MacConkey plates were invariably rich cultures; more than half the positive cultures on deoxycholate citrate medium showed less than ten colonies. The whole experiment was repeated using a batch of deoxycholate citrate medium made in another laboratory and the same result was obtained.

In a third trial equal volumes of dilutions of faeces were introduced into tubes of selenite broth and tubes of sterile tap water. At the same time they were plated out on brilliant green MacConkey's medium. The selenite broth yielded thirty-four positives, the tap water twenty-four and the direct plating twenty-six. If this experiment had been carried out in the early stages of the disease it is probable that plating from the tubes of tap water would have shown advantages over direct plating on a solid medium.

The value of special broths is undoubtedly great, but it must be admitted that ordinary nutrient broth may often have a high value also. For example, Thomson (1953) reported that $S a l m$. paratyphi $B$ survived in a sample of flour for nearly a year. This result was obtained by making the primary culture in nutrient broth; cultures made in selenite broth were negative after the fifth month. The results of the experiments described here suggested that intestinal pathogens are not suppressed when growing in ordinary nutrient broth along with Bact. coli, etc. On the surface of a MacConkey plate, however, the pathogens are often found only with difficulty if at all.

\section{SUMMARY}

1. Gastro-enteritis caused by certain varieties of Bact. coli is a highly infectious disease among babies, and it has been suspected that the infectivity is associated, partly at least, with the very large numbers of pathogens excreted in the faeces. Very large numbers were found in the faeces, but large numbers of pathogens were also found in dysentery, salmonella food-poisoning and in some cases of paratyphoid fever.

In cases of gastro-enteritis the dilution of faeces containing 5 to 50 pathogenic Bact. coli per ml. was usually $10^{-8}$; in Sonne dysentery and salmonella foodpoisoning the corresponding dilution was $10^{-6}$. It is doubtful if even this difference can account for the differences in infectivity. 
2. When normal Bact. coli outnumber pathogenic Bact. coli, shigellae or salmonellae by as little as 10:1 it is difficult to identify the pathogens unless a selective culture medium can be used.

3. Ordinary nutrient broth is generally able to act as an enrichment medium for the isolation of pathogens from faeces.

\section{REFERENCES}

Thomson, S. (1953). Mon. Bull. Minist. Hlth Lab. Serv. 12, 187.

Thomson, S. (1954). J. Hyg., Camb., 52, 67.

Miles, A. A. \& Misra, S. S. (1938). J. Hyg., Camb., 38, 732.

Lennox, M., Harvey, R. W. S. \& Thomson, S. (1954). J. Hyg., Camb., 52, 311.

(MS. received for publication 6. I. 55) 